\title{
Consumer perceptions and purchase behavior toward imperfect fruits and vegetables in an immersive virtual reality grocery store
}

Article

Accepted Version

Creative Commons: Attribution-Noncommercial-No Derivative Works 4.0

Lombart, C., Millan, E., Normand, J.-M., Verhulst, A., LabbéPinlon, B. and Moreau, G. (2019) Consumer perceptions and purchase behavior toward imperfect fruits and vegetables in an immersive virtual reality grocery store. Journal of Retailing and Consumer Services, 48. pp. 28-40. ISSN 0969-6989 doi: https://doi.org/10.1016/j.jretconser.2019.01.010 Available at https://centaur.reading.ac.uk/81803/

It is advisable to refer to the publisher's version if you intend to cite from the work. See Guidance on citing.

To link to this article DOI: http://dx.doi.org/10.1016/j.jretconser.2019.01.010

Publisher: Elsevier

All outputs in CentAUR are protected by Intellectual Property Rights law, including copyright law. Copyright and IPR is retained by the creators or other copyright holders. Terms and conditions for use of this material are defined in the End User Agreement. 


\section{www.reading.ac.uk/centaur}

\section{CentAUR}

Central Archive at the University of Reading

Reading's research outputs online 


\title{
Consumer perceptions and purchase behavior toward imperfect fruits and vegetables in an immersive virtual reality grocery store
}

\author{
Cindy Lombart, Elena Millan, Jean-Marie Normand, Adrien Verhulst, \\ Blandine Labbé-Pinlon, Guillaume Moreau
}

\begin{abstract}
:
This study investigates the effects of fruits and vegetables (FaVs) abnormality on consumer perceptions and purchasing behavior. For the purposes of this study, a virtual grocery store was created with a fresh $\mathrm{FaVs}$ section, where 142 participants became immersed using an Oculus Rift DK2 Head-Mounted Display (HMD) software. Participants were presented either "normal", "slightly" misshapen, "moderately" misshapen or "severely" misshapen" FaVs. The study findings indicate that shoppers tend to purchase a similar number of FaVs whatever their level of deformity. However, perceptions of the appearance and quality of the FaVs depend on the degree of abnormality. "Moderately" misshapen FaVs are perceived as significantly better than those that are "heavily" misshapen but also "slightly" misshapen (except for the appearance of fruits).
\end{abstract}

Key words:

Consumer perceptions, Purchase behavior, Imperfect fruits and vegetables, Food waste, Virtual reality grocery store, Immersive VR shopping experience, Experimental design 


\section{Introduction}

Food waste is a major issue for households, service providers (e.g., retail, restaurants, catering, and hospitality sectors), the food industry, farmers, and the environment. According to a report by the Food and Agriculture Organization (FAO, 2011) of the United Nations, roughly one third of the edible food produced in the world for human consumption every year - approximately 1.3 billion tons - gets lost or wasted. Fruits and vegetables (FaVs) including also roots and tubers (the $\mathrm{FaVs}$ commodity group) have the highest wastage rates of any food ranging between 40 and 50\%. Food waste, which results from retailers' and consumers' behavior at the end of the Food Supply Chains (FSC) for FaVs, is also substantial, with 15$30 \%$ of $\mathrm{FaVs}$ purchases discarded by consumers, mainly in supermarkets and hypermarkets, because of their imperfect appearance (FAO, 2011).

After the relaxation of the EU regulations in 2009 on the sale of FaVs with imperfect appearance (Castlenov, 2008), retailers have slowly and cautiously started offering misshapen FaVs (see Mulholland, 2014; Butler, 2016). Increased offering of this type of FaVs is not driven only by the pressing need to reduce food waste, but also by other benefits this initiative can bring to retailers, such as competitive advantage vis-à-vis other retailers, new market opportunities, improved Corporate Social Responsibility (CSR) reputation, and overall supermarket's image, and financial performance (e.g., Butler, 2016).

During the years a major deterrent for the retailers to begin offering misshapen FaVs has been their belief that consumers would not buy FaVs which have the "wrong" size and shape, and thus appearance (de Hooge et al., 2017). After the scrapping of the EU "marketing standards" about the appearance, weight and size of fresh produce, the following question begs an answer: "What are consumers' perceptions and behavior toward imperfect FaVs?" Retailers need to have a good understanding of these issues in order to make better predictions about consumer behavior with regard to imperfect FaVs. Such knowledge will help them to develop effective market offers of misshapen $\mathrm{FaVs}$ in their supermarkets, by considering the degrees of shape abnormality of the FaVs that will be acceptable by consumers. This knowledge will also allow them to avoid further food waste in distribution centers and retail outlets.

Recently, the problem of $\mathrm{FaVs}$ waste due to their cosmetic imperfections has been increasingly debated in the public domain (e.g., in FAO and EU documents, the popular press and the Internet space). However, to date academic research on consumer behavior toward imperfect FaVs is still scarce. Specifically, two studies have examined consumers' purchase intentions toward abnormally shaped fresh produce with different levels of abnormality (i.e., normal, moderately abnormal, and extremely abnormal) (Loebnitz et al., 2015 a,b). The studies found that severe but not moderate food shape abnormalities influence consumers' purchase intentions. While these studies offer some valuable insights about the effects of food shape abnormality on consumers' purchase intentions, their expected effect of the moderately misshapen FaVs was not confirmed. Also, three levels of food shape abnormality were considered in both studies. Finally, in the two studies food shape abnormality was manipulated through pictorial stimuli. To the best of our knowledge, there is no previous research exploring consumers' perceptions about the appearance, quality and price fairness, and purchase behavior toward FaVs with four different levels of shape abnormality in the context of a VR supermarket. The present study addresses these issues by exploring: (a) whether shoppers' perceptions of appearance, quality, and price fairness of FaVs are affected by the degree of their deformity; and (b) whether consumers purchase a similar number of FaVs regardless of their degree of deformity. 
Instead of using pictures or "classical" marketing techniques to study consumers' perceptions and purchasing behavior in real shops, our study utilizes a virtual grocery store created for the purpose. Recent evidence suggests that shopping behavior in a VR store is likely to be more similar to the behavior in the physical store compared to the pictorial representation of a number of food products (van Herpen et al., 2016). However, VR has not been applied to address research questions similar to those of the present research. VR could be a valuable tool for conducting marketing studies with quickly perishable food products, such as fresh $\mathrm{FaVs}$. By replacing real fresh products with virtual ones two important methodological issues can be better addressed: (a) replicating more easily existing consumer studies, and (b) better control of different aspects of food appearance (e.g., misshapen FaVs) and evaluation of participants' shopping behavior. Indeed, the variability and the perishable nature of fresh produce make it very difficult to replicate consumer studies with a large number of participants. Moreover, fresh food products quickly deteriorate over time, and this can be further accelerated by the fact that study participants have to physically examine the products during the experiments.

The research contributes to existing knowledge by exploring for the first time the effects of different degrees of shape imperfection of $\mathrm{FaVs}$ on consumers' perceptions and purchase behavior in an immersive VR supermarket environment. The study findings have important implications for food retailers too. In addition to helping them to develop effective market offers of misshapen FaVs, and thus to avoid further food waste, the findings can also sensitize food retailers to the need to tackle any existing consumers' misconceptions with regard to appearance flaws and quality of misshapen FaVs by educating them about the latest scientific knowledge on these issues, as well as about the implications of food waste on farmers' wellbeing and the sustainability of the environment.

\section{Literature review and study hypotheses}

\subsection{The use of VR in consumer behavior and food retailing studies}

The use of VR in marketing studies has been growing with the recent advances in this technology. For instance, VR is very useful for testing new products, and particularly disruptive one (Dahan and Hauser, 2002; Ottosson, 2002; Kim et al., 2011), by using virtual prototyping (VP). VP involves building and analyzing computer models of new products (Wang, 2002) to reduce time and costs for intensive manufacturing and testing of the prototypes (Bordegoni et al., 2010). In the three dimensional computer-generated environments, users can interact with and manipulate a realistic representation of the products-modifiable in some cases (Bordegoni and Caruso, 2012; Ferrise et al., 2013)-in real time. VR facilitates users' interactive exploration of new products, their better understanding of the features and benefits of the products presented, for instance, in a conjoint analysis (Dahan and Hauser, 2002; Backhaus et al., 2014). Hence, VP use can lead to more reliable answers or new ideas proposed by users (Füller and Matzler, 2007). The use of VP is best suited for complex products or situations, where physical prototyping is impractical, impossible or inefficient (Liu and Campbell, 2008). For simple products or products where high fidelity of ergonomics and functionality is necessary, a physical prototype seems to be the better choice (Erik, 2015).

As to interactive virtual prototyping (IVP), it allows users to engage some of their senses (i.e., sight, hearing, and touch) during their interaction with the prototype (Bordegoni et al., 2006; 
Ferrise et al., 2010). Interactive virtual prototypes differ from traditional virtual prototypes, with the latter allowing users to interact only passively through their vision. Thus, VP is mainly suitable for evaluating product aspects by relying only on vision, such as color, affordances and visibility, while IVP, which may also include haptic modalities, is more suitable for evaluating product aspects such as usability and comfort (Erik, 2015).

VR allows researchers and professionals to realistically and efficiently recreate virtual supermarkets, as well as the flexibility to quickly modify their layout and the goods displayed. However, consumer research using immersive virtual stores is still rare. The following studies are worth mentioning. Pantano and Servidio (2012) investigated consumers' responses toward the introduction of immersive environments (based on the 3D virtual reality) in traditional points of sale. They found that consumers' level of satisfaction toward this innovative tool was influenced by three factors, namely, its perceived usefulness, the enjoyment provided by it, and the perceptions of the new store created thereby. Other researchers explored how the characteristics of the virtual store, created independently of a real one (e.g., level of realism of the virtual environment, colors used, design of the store, etc.), affected users' experience (e.g., interest, enjoyment, satisfaction) and purchase behavior (Massara et al., 2010; Papagiannidis et al., 2013; Wu et al., 2013). Finally, in a 3D web-based virtual supermarket environment specifically created, Waterlander et al. $(2012,2013)$ found that discounts on healthy foods $(10 \%, 25 \%$, and $50 \%)$ were effective (50\% was the most effective) in stimulating consumers' purchases, whereas the discounts did not lead to higher expenditures in the unhealthier food categories (e.g., desserts, soda, crisps, candy, and chocolate) (Waterlander et al., 2012). These studies indicate that VR is a useful tool for conducting consumer behavior experiments in general (e.g., Pantano and Servidio, 2012), and in the context of food preferences and consumption in particular (e.g., Waterlander et al., 2011, 2012, 2013).

At the end of this discussion it is worth noting that the vast majority of these studies use desktop VR systems. What is more, with the exception of Waterlander et al. (2011, 2012, 2013), none of them considered fresh food, and more specifically FaVs. When some fresh $\mathrm{FaVs}$ were offered to consumers in the web-based 3D supermarket, no variability was integrated (for instance, a single 3D model was used for each type of FaV). Finally, none of these VR stores utilized a Head-Mounted Display (HMD) software (such as Oculus Rift DK2 used in the present study) to improve users' immersion.

\subsection{Consumers' perceptions and purchase behavior toward imperfect fruits and vegetables}

The present study anticipates that consumers' perceptions (of the FaVs' appearance, quality, and price fairness) and purchase behavior toward FaVs will vary across the different degrees of their imperfection, even though their objective quality may not be different from that of the perfectly shaped ones (see Symmank et al., 2018).

The cue utilization theory (Olson, 1978) is a useful framework to explain consumers' perceptions and purchase intentions toward misshapen FaVs. According to this theory, products offer different cues that consumers use in their product evaluations, which in turn determine purchase decisions. To make purchase decisions, consumers form expectations from intrinsic and extrinsic product cues. Extrinsic cues are products' attributes which are not part of the physical products (e.g., price, packaging, label). They can be changed easily without modifying the physical properties of the products (Richardson et al., 1994; Akdeniz et al., 2013). By contrast, intrinsic cues are attributes which are part of the physical products 
(e.g. ingredients, shape, color). As such, they cannot be manipulated without altering the physical properties of the product itself (Olson, 1978; Bello Acebron and Calvo Dopico, 2000; Akdeniz et al., 2013). The present study consider FaVs' appearance as an intrinsic cue that will influence consumers' perceptions, evaluations, and purchase decisions. Appearance of FaVs provides informational cues about their quality and ease of use, due to longestablished, deeply ingrained associations of $\mathrm{FaVs}$ with perfect appearance, as well as to past purchase experiences with fresh produce.

Further light on the role of FaVs' appearance in consumer decision making can be shed by neuroaesthetics, which studies the neural processes related to aesthetic experience of beauty (see Cinzia and Vittorio 2009; Chatterjee 2014). Within this theoretical account it is argued that our aesthetic appreciation of objects is the outcome of complex interactions involving different brain areas associated with perceptual, emotional, and cognitive processing. Aesthetically pleasant visual stimuli tend to attract more attention, enhanced cognitive processing and rewarding experiences, whereas less attractive ones tend to elicit a negative emotion-related neural response (see Righi et al., 2017). Related to the latter effect, the principle of negativity bias can explain consumers' avoidance of severely misshapen food products. The gist of this principle is that "negative events are more salient, potent, dominant in combinations, and generally efficacious than positive events" (Rozin and Royzman. 2001, p. 297). The negativity bias is particularly well manifested in the domain of contagion and the law of contagion, according to which when entities get in contact, between them passes some "essence", which leaves a permanent trace (Rozin and Royzman. 2001, p. 305). As severely misshapen FaVs can pose food safety risks, consumers would reject those food products because of contagion beliefs and the perceived need to protect themselves against physical contamination.

For the last few decades, Western consumers have become accustomed to buying flawless FaVs. In other words, buying flawless FaVs has become the norm and the reference point for their evaluation. The lack of variation in the FaVs' appearance due to its regulation by the aforementioned marketing standards, and past purchase experiences with buying flawless $\mathrm{FaVs}$, have reinforced consumers' expectations to buy only perfectly-shaped fresh produce. Besides, growing affluence has made the average Western consumer less sensitive toward the prices they pay for their FaVs. Last but not least, until a decade or so ago, there has been no public debate on the topic of food waste in general, and the role of retailers and households' consumption in exacerbating this problem in particular. Consequently, on the whole consumers have not been aware of the diverse implications (e.g., economic and environmental) of their food choices. Thus, their shopping preferences and behavior toward fresh produce have remained largely unquestioned for a long period of time. As a result, consumers' perception of the appearance of the more heavily misshapen FaVs is likely to be less favorable than their perceptions of the slightly misshapen and standard fruits and vegetables. Indeed, the visual appearance or shape of food constitutes consumers' first sensory impression, resulting in particular inferences about food product quality (Bitner, 1992; Bloch, 1995). Visual appearance properties, including shape (Hurling and Shepherd, 2003; Wansink, 2004), also influence consumers' likes and dislikes, leading to acceptance or rejection of food (Cardello, 1994). The neuroaesthetics theory and evidence provides further support to this notion.

In line with this discussion, Barbe et al. (2017) report that most German consumers are still not well informed and do not understand well food loss and waste. They also found that consumers' perception of "ugly" appearance of the misshapen FaVs was one of the reasons 
for avoiding purchasing them. Another large-scale research with consumers from five Northern European countries revealed that for all suboptimal products studied, among which cucumbers and apples, their attractiveness and food safety (except for cucumbers) were important factors in consumers' decision to choose the suboptimal product (de Hooge et al., 2017).

With regard to consumers' perception of quality, taste and nutritional properties of misshapen FaVs may be the same as those of FaVs with no abnormalities (see Symmank et al., 2018); however, misshapen FaVs' quality related to ease of preparation, sanitary quality, and in some cases durability may be affected by the flaws in their shape. Some additional loss of the FaVs can also occur during pealing. Because of the long-established retailers' practices to offer perfectly-shaped $\mathrm{FaVs}$, shape abnormality of FaVs is likely to be viewed as a negative quality cue (Bitner, 1992; Bloch, 1995). To put it differently, FaVs that deviate from the established norm are likely to be perceived being of inferior or less desirable quality (see Loebnitz et al., 2015b). Consistent with this notion, Barbe et al. (2017) study found that respondents who held positive attitudes toward misshapen vegetables were more likely to purchase them because of perceived lack of quality differences with the flawless ones. However, those who were not willing to buy such fresh produce believed that misshapen vegetables tend to turn bad more quickly, to be of inferior taste relative to the perfectly shaped ones, as well as to be harder to peal. The above discussion of the negativity bias and the law of contagion shows that more severe deformations, such as broken skin of the FaVs (e.g., cicatrisations) or spots, can be seen as a source of potential contamination and health and safety hazards (e.g., de Hooge et al., 2017). Consequently, the favorability of consumers' perception of the quality of the FaVs may vary across the FaVs with different degrees of deformation.

As to consumers' perception of price fairness, it is likely to be less favorable for the more heavily misshapen ones in scenarios when FaVs with different degrees of abnormality are priced at the same level. This is because of the imperfections and some negative associations held about the misshapen FaVs, not to mention the fact that the "ugly" FaVs will compete with the "beautiful" ones on the supermarket shelves. In other words, FaVs with greater deformation could be perceived as less attractive and of lower quality than those with lesser deformation (see Loebnitz et al., 2015b). Therefore, it seems sensible the more heavily misshapen $\mathrm{FaVs}$ to be offered at a discounted price than the perfectly-shaped ones. The lower price is likely to create an impression of price fairness and thus to increase their market appeal. Indeed, de Hooge et al.'s (2017) research shows that price discounts are important for motivating the purchase of suboptimal food products. Similar finding is reported by Symmank et al. (2018) in their study of consumer behavior toward suboptimal bananas (i.e., bananas with brown spots) versus normal ones (i.e., yellowish-green bananas with no spots). Barbe et al. (2017) also report that the percentage of respondents who would buy vegetables with cosmetic flaws more than doubled in the scenario where the imperfect vegetables were cheaper than their flawless counterparts. Given this evidence, it is reasonable to expect that when imperfectly-shaped and perfectly-shaped $\mathrm{FaVs}$ are priced at the same level, consumers will be more willing to buy FaVs with less imperfections.

Finally, with regard to purchase behavior, Barbe et al. (2017) found that German consumers were more willing to buy vegetables with connations (i.e., less severe) than with cicatrisations (i.e., more severe) cosmetic flaws. Along similar lines, Loebnitz et al. (2015b) report that FaVs' shape imperfections influence Danish consumers' purchase intentions, but only if the $\mathrm{FaVs}$ deviate extremely from the norm. No differences in purchase intentions were found for moderately abnormal FaVs. Another study by Loebnitz et al. (2015a) found that Chinese 
consumers are more likely to purchase perfectly-shaped fruits and vegetables than moderately or extremely misshaped ones. Last but not least, Symmank et al. (2018) study discovered that German consumers' purchase intention was significantly lower for the visually suboptimal bananas before and after their tasting.

The above discussion leads to the following hypotheses:

H1. Consumers' perceptions of (a) appearance, (b) quality, and (c) price fairness of the moderately and heavily misshapen $\mathrm{FaVs}$ will be less favorable than their perceptions of the slightly misshapen and standard FaVs in a virtual supermarket environment.

H2. Consumers will buy less of the moderately and heavily misshapen FaVs compared to the slightly misshapen and standard FaVs priced at the same level in a virtual supermarket environment.

\section{Methodology}

This section discusses the following methodological issues: (a) the design of the virtual supermarket, including a fresh produce stand filled in with FaVs; (b) the experimental protocol developed; and (c) the measurement scales used and their psychometric properties.

\subsection{Our immersive VR supermarket}

The VR supermarket designed for the purposes of this research mimics the Audencia Business School IN SITU store laboratory, where consumer studies are carried out on real (nonperishable) food products. Our VR supermarket had four shelves filled in with non-perishable food products (e.g., rice, pasta), a cashier and a door (see Figure 1). Non-perishable food products were hand-modeled using products' real dimensions and textured with high resolution pictures taken from the real products. In addition, our VR supermarket had a fresh produce stand (see Figure 2), which was modeled after real life examples and filled in with eight families of FaVs: four fruits (i.e., oranges, bananas, pears (conference variety), and apples (Granny Smith)), and four vegetables (i.e., potatoes, zucchinis, carrots, and tomatoes (round)). These FaVs were chosen because they were seasonal at the time of collecting the data. The different types of FaVs were displayed in 18 baskets. Each basket held between 12 and 15 items of the same FaVs' type. The only information displayed about the FaVs was their name and price per kilogram, the latter being calculated as the average of the prices observed in three neighboring hypermarkets and supermarkets.

[Figure 1 in here]

[Figure 2 in here]

\subsection{Experimental protocol}

A total of 142 participants (92 female and 50 male, aged between 19 and 23 years) from Audencia Business School took part in the study experiment. With regard to their previous experience with VR, 103 participants $(72.5 \%)$ had no such experience and $39(27.5 \%)$ had some experience.

Using a between-subjects design (i.e., four groups and an after-only design), the participants were randomly assigned either to the control group (hereafter called Group 0) or one of the three manipulated groups (called groups 1,2, and 3), each corresponding to a different degree 
of appearance abnormality in terms of size and shape of the FaVs studied. The allocation of the study participants to each of the four groups is as follows:

1. Group 0: "normal" FaVs, 35 participants (control group that corresponds to standard or flawless $\mathrm{FaVs}$ that are typically sold in supermarkets and hypermarkets)

2. Group 1: "slightly" misshapen FaVs, 36 participants

3. Group 2: "moderately" misshapen FaVs, 35 participants

4. Group 3: "heavily" misshapen $\mathrm{FaVs}, 36$ participants

$\mathrm{FaVs}$ of the eight $\mathrm{FaVs}$ families considered in the experiment were semi-automatically generated for each of the four conditions studied (see Figure 3 and Appendix 1).

\section{[Figure 3 in here]}

To validate the homogeneity of the groups formed, chi-square analysis and non-parametric ANOVA (Kruskal-Wallis test) were conducted. The four groups were homogeneous with regard to sex composition $\left(X^{2}=1.308 ; p=0.73\right)$, age $\left(X^{2}=3.384 ; p=0.34\right)$, and level of food waste consciousness, measured with six items on a six-point Likert scale (see Le Borgne et al., 2015): construct reliability $(C R)=0.947$, average variance explained $(A V E)=0.583$, $\min$ $=15, \max =36, \mathrm{M}=30.00$, standard deviation $(\mathrm{SD})=4.554, \mathrm{X}^{2}=3.153 ; \mathrm{p}=0.37$.

Before the start of the experiment, the study participants signed a consent form. They were then briefed about how to use the VR equipment. The participants were also explained that they were going to be immersed in a virtual supermarket environment and that they could leave the experiment at any time if they felt dizzy or unwell. A training session was held to show the study participants how to interact with the VR supermarket, or more specifically, how to navigate, select, manipulate and buy the FaVs. The participants were then presented with the respective scenario of the experiment (see Figure 4). If a participant had questions regarding the scenario, (s)he was encouraged to seek clarification from a researcher, who also monitored the participants, helping them with the use of the equipment, or if they felt unwell.

[Figure 4 in here]

Next, the participants sat comfortably on a chair in front of a desk and immersed in the VR supermarket, which was designed using an Oculus Rift DK2 HMD (see Figure 5). Given the size of the VR supermarket (approximately $96 \mathrm{~m}^{2}$ ), as well as the number of participants, an Xbox One controller was used instead of motion tracking based navigation metaphor. Headtracking was achieved using the optical camera from the DK2, and the application ran on a workstation powerful enough to ensure a stable framerate of $75 \mathrm{~Hz}$.

In the VR supermarket, the participants navigated as follows: they could move forward and backward using the left thumbstick of the controller. The walking direction was controlled either by the gaze direction (i.e., HMD movements) or by the right thumbstick (in this case the rotation speed was limited in order to reduce dizziness). The walking speed was adjusted to that of a normal real pace. The user could interact with virtual objects in a number of different ways, such as selecting, manipulating (i.e., rotating), purchasing, or putting back a virtual object. This was achieved using two buttons and one joystick of the controller.

After being immersed in the VR supermarket, the participants had to walk through the store (in order to increase the feeling of being in a store) before reaching the fresh produce stand. There, they inspected and chose the FaVs they decided to buy-as mentioned in the experimental scenario, they were not obliged to buy FaVs if they did not want to. At any time 
during the experiment, the participants could access the content of their virtual shopping cart by pressing a button on the controller (the one used for purchasing when an object is selected). A virtual window with the list of the purchased products was then displayed. Each product had its name (e.g., carrot, apple) and price displayed, as well as the total value of the whole shopping cart.

Finally, once the participants were satisfied with the FaVs they chose, they had to go to the virtual cashier to complete the experiment. For each participant, the deformation level of the FaVs (i.e., "normal", "slightly" misshapen, "moderately" misshapen, and "heavily" misshapen), the total number of FaVs purchased, and the amount of money spent by FaVs family (i.e., fruits or vegetables), the time spent looking at the FaVs per family (i.e., fruits or vegetables), as well as the total amount of time spent were recorded. Once the experiment was completed, the participants were asked to fill in the study questionnaire.

[Figure 5 in here]

\subsection{Questionnaire measures}

Consumers' perceptions of the appearance and quality of the FaVs were measured with six items each, drawn from Aurier and Siriex (2009). Consumers' perceptions of the price fairness of $\mathrm{FaVs}$ were measured with two items from Bolton et al. (2010). Given the topic of the present study and the potential for social desirability bias (see Cox, 1980), 6-point Likert scales were used to avoid the selection of a neutral position. This choice seems reasonable given that food waste has a clear bias toward social acceptance. According to Cialdini's (2007) principle of 'Social Proof', people want to behave as the group they belong to or want to belong to, and food waste is not an acceptable behavior.

Confirmatory factor analysis (CFA) was performed with partial least squares method (PLS) and a bootstrap procedure with 500 replications (Tenenhaus et al., 2005). The PLS method was used for two main reasons: first, it does not require the variables to follow a multivariate normal distribution; and second, it works well with small samples (Hair et al., 2012). The analysis was conducted with XLSTAT 2016 software.

CFA validated the expected one-dimensional factor structures of the study constructs (namely, appearance, quality, and price fairness), which is also consistent with previous research (Aurier and Siriex, 2009; Bolton et al., 2010). Multi-group analyses and permutation tests were conducted to establish measurement invariance across the four subgroups studied (i.e., groups 0 to 3). For each factor loading, a significance test was performed on the difference between the values obtained for each of the four subgroups for both fruits and vegetables (Chin and Dibbern, 2010). These additional analyses revealed partial invariance of the measures used for the four subgroups studied for both fruits and vegetables. Of the 168 differences calculated, 7 were significant at the 5\% level. Furthermore, all factor loadings were above 0.5 and statistically significant at the $1 \%$ level for the four subgroups for both fruits and vegetables (see Appendix 2).

Next, Jöreskog's rhô coefficients (Jöreskog, 1971) were estimated to establish construct reliability for the four subsamples studied. The coefficients were above 0.7 for all subsamples for both fruits and vegetables (see Appendix 3). Finally, the convergent and discriminant validity of the measures (for all subsamples for both fruits and vegetables) was ascertain using Fornell and Larcker's (1981) approach (see Appendix 4). Evidence for discriminant validity 
was found by following the approach proposed by Henseler et al. (2015). The values in Appendix 5 below the thresholds of 0.90 and 0.85 confirm the discriminant validity of our measurement scales. These analyses confirmed the reliability and validity of the measurement tools used for all subsamples for both fruits and vegetables.

\section{Data analysis}

Before examining consumers' perceptions and purchase behavior toward imperfect FaVs in our immersive virtual reality grocery store, we analyzed if consumers shared a comparable experience in terms of presence in the virtual store, as well as if the interaction mechanisms proposed in it (via the Xbox One controller) allowed them to navigate and manipulate the FaVs objects in an easy manner. Consumers' levels of presence and ease of interaction with the VR technology used were measured with four and eight items, respectively (Witmer et al., 2005). The construct reliability (CR) and average variance explained (AVE) are satisfactory for these two constructs (CR are respectively equal to 0.867 and 0.921 (>0.7) and AVE are respectively equal to 0.627 and $0.594(>0.5)$ ).

Kruskal-Wallis analysis of variance was performed. This is a rank-based nonparametric test that is used to determine if there are statistically significant differences between two or more groups of an independent variable on a continuous dependent variable. The test replaces all scores with their rank numbers, so that higher scores get higher rank numbers. If the grouping variable doesn't affect the ratings, then the mean ranks should be roughly equal and this should be confirmed by a chi-square test. Tables 1,2 and 3 hereafter report the mean ranks within each group or relative ranks, as well as the results the chi-square tests.

Kruskal-Wallis analysis of variance revealed that the participants of the four subgroups studied (i.e., groups 0 to 3$)$ reported comparable levels of presence $\left(X^{2}=3.544 ; p>0.05\right)$ and ease of interaction $\left(\mathrm{X}^{2}=4.220 ; \mathrm{p}>0.05\right)$. The relative ranks remained largely constant (see Table 1).

\section{[Table 1 in here]}

As the study participants reported comparable levels of presence and ease of interaction within our VR supermarket, we next compared their perceptions of (a) appearance, (b) quality, and (c) price fairness of the FaVs studied, as well as their purchase behavior toward these products. Kruskal-Wallis analysis of variance revealed the following differences among the four subgroups studied for FaVs appearance and quality: fruits appearance $\left(\mathrm{X}^{2}=6.601 ; \mathrm{p}\right.$ $=0.09)$, fruits quality $\left(X^{2}=10.336 ; p<0.05\right)$, vegetables appearance $\left(X^{2}=9.347 ; p<0.05\right)$, vegetables quality $\left(\mathrm{X}^{2}=14.839 ; \mathrm{p}<0.01\right)$. This analysis was followed by pair-wise comparisons, which indicated several differences among the four subgroups studied for FaVs appearance (see Table 2):

- consumers prefer the appearance of the "normal" FaVs (group 0) compared to the "heavily" misshapen fruits $\left(\mathrm{X}^{2}=3.803 ; \mathrm{p}=0.05\right)$ and vegetables $\left(\mathrm{X}^{2}=4.570 ; \mathrm{p}<0.05\right)$ (group 3);

- consumers prefer the appearance of the "moderately" misshapen vegetables (group 2) compared to the "slightly" misshapen vegetables $\left(\mathrm{X}^{2}=3.839 ; \mathrm{p}=0.05\right)$ (group 1);

- consumers prefer the appearance of the "moderately" misshapen FaVs (group 2) compared to the "heavily" misshapen fruits $\left(\mathrm{X}^{2}=5.704 ; \mathrm{p}<0.05\right)$ and vegetables $\left(\mathrm{X}^{2}=7.296 ; \mathrm{p}<\right.$ 0.01) (group 3). 
The performed pair-wise comparisons also indicated some differences among the four subgroups studied (i.e., groups 0 to 3 ) for both FaVs quality (see Table 2):

- consumers prefer the quality of the "normal" FaVs (group 0) compared to the "slightly" misshapen fruits $\left(\mathrm{X}^{2}=3.296 ; \mathrm{p}<0.10\right)$ and vegetables $\left(\mathrm{X}^{2}=3.683 ; \mathrm{p}<\right.$ $0.10)$ (group 1) and to the "heavily" misshapen fruits $\left(\mathrm{X}^{2}=3.533 ; \mathrm{p}<0.10\right)$ and vegetables $\left(X^{2}=5.775 ; p<0.05\right)($ group 3$)$;

- consumers prefer the quality of the "moderately" misshapen FaVs (group 2) compared to the "slightly" misshapen fruits $\left(X^{2}=6.224 ; \mathrm{p}<0.01\right)$ and vegetables $\left(X^{2}=8.465 ; p\right.$ $<0.01$ ) (group 1);

- consumers prefer the quality of the "moderately" FaVs (group 2) compared to the "heavily" misshapen fruits $\left(\mathrm{X}^{2}=6.848 ; \mathrm{p}<0.01\right)$ and vegetables $\left(\mathrm{X}^{2}=10.510 ; \mathrm{p}<\right.$ 0.01) (group 3).

As to price fairness, Kruskal-Wallis analysis of variance indicated no significant differences among the four groups: fruits price fairness $\left(\mathrm{X}^{2}=3.286 ; \mathrm{p}=0.35\right)$, and vegetables price fairness $\left(\mathrm{X}^{2}=6.151 ; \mathrm{p}=0.10\right)$. However, the performed pair-wise comparisons revealed that the participants reported the prices of the "heavily" misshapen FaVs to be less fair than the prices of the "moderately" misshapen fruits $\left(\mathrm{X}^{2}=2.717 ; \mathrm{p}=0.10\right)$ and vegetables $\left(\mathrm{X}^{2}=\right.$ 6.764; $\mathrm{p}<0.01$ ) (see Table 2).

[Table 2 in here]

Therefore, our first hypothesis (H1), which postulates that consumers' perceptions of (a) appearance, (b) quality, and (c) price fairness of the moderately and heavily misshapen FaVs will be less favorable than their perceptions of the slightly misshapen and standard FaVs in a virtual supermarket environment, is partially supported by our data. Consumers' perceptions of (a) appearance, (b) quality of the heavily misshapen FaVs are less favorable than their perceptions of standard $\mathrm{FaVs}$ in a virtual supermarket environment.

As to $\mathrm{FaVs}$ purchase behavior, our Kruskal-Wallis analysis of variance did not reveal any significant differences among the four subgroups studied: fruits purchase behavior $\left(\mathrm{X}^{2}=\right.$ 2.016; $\mathrm{p}=0.57)$, and vegetables purchase behavior $\left(\mathrm{X}^{2}=0.415 ; \mathrm{p}=0.94\right)$. Nonetheless, the Kruskal-Wallis analysis of variance revealed significant differences among the four groups on the time spent to purchase fruits $\left(\mathrm{X}^{2}=9.877 ; \mathrm{p}<0.05\right)$. More specifically, consumers spent more time $\left(\mathrm{X}^{2}=9.523 ; \mathrm{p}<0.01\right)$ to purchase "heavily" misshapen fruits (group 3) compared to "slightly" misshapen fruits (group 1). Similarly, consumers spent more time $\left(X^{2}=3.096 ; p\right.$ $=0.08$ ) to purchase "heavily" misshapen fruits (group 3) compared to "moderately" misshapen fruits (group 2).

With regard to the time spent to purchase vegetables, the differences were not significant among the four groups $\left(\mathrm{X}^{2}=3.440 ; \mathrm{p}=0.33\right)$. The pair-wise comparisons indicated only one significant difference, namely, consumers spent more time to purchase "heavily" misshapen vegetables (group 3) compared to "slightly" misshapen vegetables (group 1): $\mathrm{X}^{2}=2.930 ; \mathrm{p}<$ 0.10 .

[Table 3 in here]

Consequently, our second hypothesis (H2), which postulates that consumers will buy less of the moderately and heavily misshapen FaVs compared to the slightly misshapen and standard 
FaVs priced at the same level in a virtual supermarket environment is not supported by our data.

\section{Discussion of results}

\subsection{Summary of findings}

The present study found that in a virtual supermarket environment consumers tend to prefer "normal" FaVs in terms of appearance rather than "heavily" misshapen ones. This finding is consistent with our prior expectation grounded in different theoretical accounts, as well as retailers' practices during the last few decades of selling flawless $\mathrm{FaVs}$, which have shaped consumers' expectations about FaVs appearance and established the reference point for their evaluation. Our findings are also in line with Barbe et al. (2017), de Hooge et al. (2017), and Righi et al. (2017). Our research also found that consumers preferred the appearance of the "moderately" misshapen FaVs compared to the "heavily" misshapen ones. Interestingly, stronger preference was found for the appearance of the "moderately" misshapen FaVs compared to their "slightly" misshapen counterparts (except for the appearance of fruits). This finding, which is at odds with our expectation, is discussed further below.

With regard to consumers' perceptions of the quality of the FaVs, this study found that consumers prefer the quality of the standard FaVs compared to the "slightly" and "heavily" misshapen FaVs. These findings are consistent with the cue utilization theory, as well as the principle of negativity bias and the law of contagion. Our findings are also in accord with Barbe et al. (2017) and de Hooge et al. (2017). Also, consumers seem to prefer the quality of the "moderately" misshapen FaVs compared to the "heavily" misshapen ones. Furthermore, similar to our finding about consumers' preference of the appearance of the "moderately" misshapen FaVs compared to their "slightly" misshapen counterparts (except for the appearance of fruits), consumers appear to prefer the quality of the "moderately" misshapen FaVs compared to the "slightly" misshapen ones.

These findings highlight some interesting issues. To start with, it seems that there is a threshold above which FaVs are too heavily misshapen, and thus are perceived as being of poor quality (see de Hooge et al., 2017). Besides, there seems to exist a "minimum deformation threshold", under which FaVs are not perceived to be of good quality, most likely because if they are not misshaped at all, participants may perceive such FaVs as "industrial" and thus less healthy and less tasty. This notion is supported by our findings that "moderately" misshapen FaVs are perceived as better in terms of appearance and quality than the "slightly" (except for the appearance of fruits) and "heavily" misshapen FaVs. Given also that the differences between the "moderately" misshapen FaVs and "normal" FaVs are not significant, these results suggest that a "minimum deformation level" (i.e., moderate deformation) may lead to participants' perception of such FaVs as healthier, less industrial, and overall better for them.

With regard to price fairness, this study found the prices of the "heavily" misshapen FaVs to be perceived as less fair than the prices of the "moderately" misshapen FaVs only (more notably for the vegetables' subgroups). These findings are at odds with previous studies (Barbe et al., 2017; Briggs, 2017; de Hooge et al., 2017; Symmank et al., 2018), all of which suggested that price discounts are important for motivating the purchase of suboptimal food products. 
Our findings of lack of difference in consumers' purchases of FaVs with different levels of deformity are at variance with Loebnitz et al. (2015a, b), who found that FaVs' shape imperfections influence consumers' purchase intentions when the appearance of FaVs deviates extremely from the norm. Even if the differences are not significant, our results showed that consumers bought less of the moderately and heavily misshapen FaVs compared to the standard and slightly misshapen FaVs. These results may be due to consumers' high level of food waste consciousness. As French retailers have taken the lead in Europe to sell imperfect FaVs (see Mulholland, 2014), and as this initiative has been extensively covered in the press, this may explain why French consumers are generally more willing to buy FaVs with appearance flaws.

\subsection{Theoretical and managerial implications}

This research has found no significant differences in the number of FaVs bought by consumers at the different deformation levels of the FaVs. The possible cognitive dissonance related to the "heavily" misshapen FaVs, where consumers' purchase behavior was not in line with their perceptions of FaVs quality (these $\mathrm{FaV}$ were perceived to be of lesser quality than the standard and "moderately" misshapen FaVs) suggest that retailers have still to work on changing consumers' perceptions and "educate" these consumers that "ugly" FaVs are beneficial both for them (e.g., nutritious, tasty, economical) and for the environment (i.e., by reducing food waste). Such educational campaigns could also have a more symbolic societal role: to sensitize people to be more accepting of differences, as demonstrated by recent retailers' campaigns (e.g., Intermarché in France, Tesco in the UK). Also, only one significant difference emerged when comparing the prices of the FaVs, namely, that "moderately" misshapen vegetables are perceived to have a fairer price compared to the "heavily" misshapen FaVs. These findings indicate that as long as "moderately" misshapen FaVs are fairly priced, consumers will be willing to buy them.

Another important finding is that "slightly" and "heavily" misshapen FaVs were perceived to be of lesser quality than the "moderately" misshapen FaVs. These findings draw attention to the possible existence of two kinds of perceptual "thresholds" in FaVs deformation levels:

- the first threshold (i.e., upper threshold) is quite straightforward, namely, beyond a certain deformation level misshaped $\mathrm{FaVs}$ stop being perceived to be of quality by our participants;

- the second threshold (i.e., lower threshold) is a minimum acceptable deformation level since our FaVs from condition 1 (i.e., "slightly misshaped" FaVs) are seen to be of lower quality than those from conditions 2 and 3 , while being less misshaped.

These two thresholds suggest that retailers may have two main options regarding their fresh produce offers and the needs of their consumers:

- they can focus on calibrated, undeformed $\mathrm{FaVs}$ to convey an image of standard, clean and nice FaVs, and thus of quality FaVs;

- they can offer "moderately" misshapen FaVs (up to a certain level) that convey an image of authentic agricultural food that is natural, healthy, and tasty, which may also help them to improve their CSR image.

Given the study findings related to price fairness (i.e., the prices of the "heavily" misshapen FaVs were perceived as less fair than those of the "moderately" misshapen FaVs), by cutting the prices of the "heavily" misshapen FaVs (for example some $30 \%$ below the price of the 
standard FaVs), retailers could counterbalance the effect of the negative quality cue of those FaVs and convince shoppers to buy them.

Finally, our results suggest that immersive VR is a promising new tool for conducting marketing studies in the food domain. VR can ensure repeatability and much more control than "traditional" studies in terms of experimental conditions. All subjects can experience the exact same conditions (same 3D products, same lighting/audio conditions, same setup). At the same time, unlike picture-based experiments and closer to in-store experiments, participants can interact with and manipulate the products even if in a somehow limited way compared to a "traditional" in-store study. VR is a real asset for studying "fresh" food products (e.g., dairy, fruits and vegetables, meat, fish), for which in-store studies prove close to impossible to achieve with large numbers of participants due to rapid deterioration of real fresh products: after conducting the experiment with a few participants, products that have deteriorated will have to be replaced by new ones, and as a result not all participants will experience the same experimental conditions.

\subsection{Study limitations and directions for future research}

The present research did not find significant differences in the number of FaVs bought by consumers in the different experimental groups. This finding differs from Loebnitz et al. (2015a), who found that consumers bought significantly less FaVs when they were extremely misshaped. This discrepancy in findings could be due, at least to some extent, to differences in how consumers were exposed to the products: photographs of one single real $\mathrm{FaV}$ in Loebnitz et al.'s (2015b) study versus several visually realistic 3D virtual FaVs in our study. This finding could also have been influenced by our experimental scenario. The study participants could have felt obliged to buy $\mathrm{FaVs}$ even if was clearly indicated in the scenario that they did not have to do so if they did not want to. The mentioning in the scenario that an amateur cook (from a famous TV show) would come to the consumer's place of residence and deliver a dinner (especially prepared for the host and his/her three guests in the chef's workshop/kitchen) could have also stimulated them to make a purchase. Therefore, additional studied on consumer behavior toward misshapen FaVs using experimental design in an interactive VR supermarket environment should be conducted. Given the generally greater exposure of French consumers to misshapen FaVs, as well as their high level of food waste consciousness, it would be beneficial to replicate the study in different national contexts, which vary on these two factors.

The present study found more pronounced differences between FaVs of different deformation levels regarding their appearance and perceived quality. If a within-subject design (one participant in all conditions) instead of a between-subject design (one participant in only one condition) was used, each participant could have noticed the differences among the four conditions in a direct way and adapt their purchase behavior according to these differences. However, given the number of subjects and experimental conditions, using a within-subject design would have required considerably more time, or the use of smaller number of experimental conditions. Future research could consider using a within-subject experimental design to test the present study's hypotheses. As to our use of a convenience sample, although it increased the internal validity of the experiment, caution should be exerted with regard to the external validity of the study findings. Consequently, this study could be replicated with a more diverse sample of consumers. 
Of course, there are some potential drawbacks with the VR application. The resource needed to develop the VR/3D environment is not negligible and could prove time consuming. Even if interacting with virtual objects is possible, with actual technologies it remains still quite difficult to replicate the tactile sensation one has when manipulating real objects. Thus, a possible issue with the VR supermarket application could be the lack of touch of the FaVs. Haptic devices (devices that can simulate the sense of touch by applying vibrations, forces or motion to the user) could be used but they are still far from being able to deliver sensations that are close to reality. In order to gain further knowledge about the usefulness of the immersive VR as a market research tool, future research can conduct an experiment where participants are presented with real and virtual misshapen $\mathrm{FaVs}$ in order to compare their consumer behavior in real and VR environments. This research will shed light on the potential influences of display (e.g., HMD versus screen), appearance (e.g., colors and textures of $\mathrm{FaVs}$ ), and interaction mechanism (i.e., being able to offer more "natural" interactions with virtual FaVs) on consumer behavior.

\section{References}

Agin, G.J. and Binford, T.O. (1976), "Computer Description of Curved Objects", IEEE Transactions on Computers, Vol. C-25, No. 4, pp. 439-449.

Akdeniz, B., Calantone, R.J. and Voorhees, C.M. (2013), "Effectiveness of marketing cues on consumer perceptions of quality: The moderating roles of brand reputation and thirdparty information", Psychology \& Marketing, Vol. 30, No. 1, pp. 76-89.

Aurier, P. and Siriex, L. (2009), Marketing des produits agroalimentaires, Dunod, Paris.

Backhaus, K., Jasper, J., Westhoff, K. Gausemeier, J., Grafe, M. and Stöcklein, J. (2014), "Virtual reality based conjoint analysis for early customer integration in industrial product development", Procedia CIRP, Vol. 25, pp. 61-68.

Barbe, F.G.T., von Dewitz, P. and Triay, M.M.G. (2017), "Understanding consumer behavior to develop competitive advantage: A case study exploring the attitudes of German consumers towards fruits with cosmetic flaws", International Journal of Academic Research in Business and Social Sciences, Vol. 7, No. 6, pp. 554-80.

Bello Acebron, L. and Calvo Dopico, D. (2000), "The importance of intrinsic and extrinsic cues to expected and experienced quality: An empirical application for beef", Food Quality and Preference, Vol. 11, pp. 229-238.

Bitner, M.J. (1992), "Servicescapes: The impact of physical surroundings on customers and employees", Journal of Marketing, Vol. 56, No. 2, pp. 57-71.

Bloch, P.H. (1995), "Seeking the ideal form: Product design and consumer response", Journal of Marketing, Vol. 59, No. 3, pp. 16-29.

Bolton, L.E., Keh, H.T. and Alba, J.W. (2010), "How do price fairness perceptions differ across culture?”, Journal of Marketing Research, Vol. 47, No. 3, pp. 564-576.

Bordegoni, M. and Caruso, G. (2012), "Mixed reality distributed platform for collaborative design review of automotive interiors", Virtual and Physical Prototyping, Vol. 7, No. 4, pp. 243-259.

Bordegoni, M., Colombo, G. and Formentini, L. (2006), "Haptic technologies for the conceptual and validation phases of product design", Computers \& Graphics, Vol. 30, pp. 377-390.

Bordegoni, M., Ferrise, F., Ambrogio, M., Caruso, F. and Bruno, F. (2010), "Data exchange and multi-layered architecture for a collaborative design process in virtual environments", International Journal on Interactive Design and Manufacturing, Vol. 4, No. 4, pp. 137-148. 
Bressoud, E. (2013), "Testing FMCG innovations: Experimental real store versus virtual", Journal of Product \& Brand Management, Vol. 22, No. 4, pp. 286-292.

Briggs, F. (2017), "Shoppers willing to buy imperfect fruit and vegetables but need a discount to incentivize them, blue yonder finds", Retail Times, February 28, 2017, https://www.retailtimes.co.uk/shoppers-willing-buy-imperfect-fruit-vegetables-needdiscount-incentivize-blue-yonder-finds/.

Butler, S. (2016), "Tesco to launch 'wonky veg' range", The Guardian, March 11, 2016, https://www.theguardian.com/business/2016/mar/11/tesco-launch-wonky-veg-rangefood-waste-fruit-vegetables.

Cardello, A.V. (1994), "Consumer expectations and their role in food acceptance", in MacFie, H.J.H. and Thomson, D.M.H. (Eds.), Measurement of food preferences, Springer, London, pp. 253-97.

Castlenov, S. (2008), "Europe relaxes rules on sale of ugly fruits and vegetables", The New $\begin{array}{llll}\text { York } \quad \text { Times, November 2008, } & \text { 12, }\end{array}$ https://www.nytimes.com/2008/11/13/world/europe/13food.html.

Catmull, E. and Clark, J. (1978), "Recursively generated B-spline surfaces on arbitrary topological meshes", Computer-Aided Design, Vol. 10, No. 6, pp. 350-355.

Chatterjee, A. (2014), "Neuroaesthetics", Trends in Cognitive Sciences, Vol. 18, No. 7, pp. 370-375.

Chin, W.W. and Dibbern, J. (2010), “An introduction to a permutation based procedure for multi-group PLS analysis: Results of tests of differences on simulated data and a cross cultural analysis of the sourcing of information system services between Germany and the USA", in Vinzi V.E., Chin W.W., Henseler J. and Wang H. (Eds.), Handbook of partial least squares concepts: Concepts, methods and applications, Springer Handbooks of Computational Statistics, New York, pp. 171-193.

Cialdini, R.B. (2007), Influence: The Psychology of Persuasion, Revised Edition, Harper Collins, New York, NY.

Cinzia, D.D. and Vittorio, G. (2009), "Neuroaesthetics: A review", Current Opinion in Neurobiology, Vol. 19, No. 6, pp. 682-687.

Cox, E.P. (1980), "The optimal number of response alternatives for a scale: A review", Journal of Marketing Research, Vol. 12, No. 4, pp. 407-422.

Dahan, E. and Hauser, J. (2002), "The virtual customer", Journal of Product Innovation Management, Vol. 19, No. 5, pp. 332-353.

de Hooge, I.E., Oostindjer, M., Aschemann-Witzel, J., Normann, A., Loose, S.M. and Almli V.L. (2017), "This apple is too ugly for me!: Consumer preferences for suboptimal food products in the supermarket and at home", Food Quality and Preference, Vol. 56, pp. 80-92.

Erik, B.L. (2015), “A review of virtual prototyping. Approaches for user testing of design solutions", Working Paper, Allen Institute for Artificial Intelligence.

FAO (Food and Agriculture Organization) (2011), "Global food losses and food waste: Extent, causes and prevention", Report from Food and Agriculture Organization of the United Nations, Mai 11, 2011, https://reliefweb.int/report/world/global-food-lossesand-food-waste-extent-causes-and-prevention

Ferrise, F., Bordegoni, M. and Graziosi, S. (2013), “A method for designing users' experience with industrial products based on a multimodal environment and mixed prototypes", Computer-Aided Design and Applications, Vol. 10, No. 3, pp. 461-474.

Ferrise, F., Bordegoni, M. and Lizaranzu, J. (2010), "Product design review application based on a vision-sound-haptic interface", Haptic and Audio Interaction Design, pp. 169179 . 
Fornell, C. and Larcker, D.F. (1981), "Evaluating structural equation models with unobservable variables and measurement error", Journal of Marketing Research, Vol. 18, No. 1, pp. 39-50.

Füller, J. and Matzler, K. (2006), "Virtual product experience and customer participation - A chance for customer-centred, really new products", Technovation, Vol. 27, pp. 378387.

Jöreskog, K. (1971), "Statistical analysis of sets of congeneric tests", Psychometrica, Vol. 36, No. 2, pp. 109-133.

Hair, J.F., Sarstedt, M., Ringle, C.M. and Mena, J.A. (2012), "An assessment of the use of partial least squares structural equation modeling in marketing research", Journal of the Academy of Marketing Science, Vol. 40, No. 3, pp. 414-433.

Henseler, J., Ringle, C.M. and Sarstedt, M. (2015), "A new criterion for assessing discriminant validity in variance-based structural equation modeling", Journal of the Academy of Marketing Science, Vol. 43, No. 1, pp. 115-135.

Hurling, R. and Shepherd, R. (2003), "Eating with your eyes: Effect of appearance on expectations of liking", Appetite, Vol. 41, No. 2, pp. 167-174.

Kim, C., Lee, C., Lehto, M.R. and Yun, M.H. (2011), "Evaluation of customer impressions using virtual prototypes in the internet environment", International Journal of Industrial Ergonomics, Vol. 41, pp. 118-127.

Le Borgne, G., Sirieix, L. and Costa, S. (2015), "La sensibilité du consommateur au gaspillage alimentaire : proposition d'une échelle de mesure", proceedings of AFM conference in Marrakech, Maroc.

Loebnitz, N. and Grunert, K.G. (2015a), "The effect of food shape abnormality on purchase intentions in China", Food Quality and Preference, Vol. 40, pp. 24-30.

Loebnitz, N., Schuitema, G. and Grunert, K.G. (2015b), "Who buys oddly shaped food and why? Impacts of food shape abnormality and organic labeling on purchase intentions", Psychology \& Marketing, Vol. 32, No. 4, pp. 408-421.

Liu, B. and Campbell, R.I. (2008), "Real time integration of user preferences into virtual, in Undisciplined!", proceedings of Design Research Society Conference in Shefflield, UK.

Massara, F., Liu, S.S. and Melara, R.D. (2010), “Adapting to a retail environment: Modeling consumer-environment interactions”, Journal of Business Research, Vol. 63, No. 7, pp. 673-681.

Mulholland, R. (2014), "Ugly' fruit and vegetables prove a hit in France: French supermarkets to expand initiative that sells "ugly" fruit and vegetables at a 30 per cent discount", The Telegraph, September 2014, https://www.telegraph.co.uk/news/worldnews/europe/france/11131994/Ugly-fruitand-vegetables-prove-a-hit-in-France.html.

Ottosson, S. (2002), "Virtual reality in the product development process", Journal of Engineering Design, Vol. 13, No. 2, pp. 159-172.

Pantano, E. and Servidio, R. (2012), "Modeling innovative points of sales through virtual and immersive technologies", Journal of Retailing and Consumer Services, Vol. 19, No. 3, pp. 279-286.

Papagiannidis, S., Pantano, E., See-To, E.W.K. and Bourlakis, M. (2013), "Modelling the determinants of a simulated experience in a virtual retail store and users product purchasing intentions", Journal of Marketing Management, Vol. 29, No. 13-14, pp. 1462-1492.

Richardson, P.S., Dick, A.S. and Jain, A.K. (1994), "Extrinsic and intrinsic cue effects on perceptions of store brand quality", Journal of Marketing, Vol. 58, No. 10, pp. 28-36. 
Righi, S., Gronchi, G., Pierguidi, G., Messina, S. and Viggiano, M. P. (2017), "Aesthetic shapes our perception of every-day objects: An ERP study", New Ideas in Psychology, Vol. 47, pp. 103-112.

Rozin, P. and E. B. Royzman (2001), "Negativity Bias, Negativity Dominance, and Contagion", Personality and Social Psychology Review, Vol. 5, No. 4, pp. 296-320.

Siegrist, M., Ung, C.-Y., Zank, M., Marinello, M., Kunz, A., Hartmann, C. and Menozzi, M. (2018), "Consumers' food selection behaviors in three-dimensional (3D) virtual reality", Food Research International, https://doi.org/10.1016/j.foodres.2018.02.033.

Symmank, C., Zahn, S. and Rohm, H. (2018), "Visually suboptimal bananas: How ripeness affects consumer expectation and perception", Appetite, Vol. 120, pp. 472-81.

Taubin, G. (1995), "A signal processing approach to fair surface design", proceedings of the 22nd annual conference on Computer graphics and interactive in New York, USA.

Tenenhaus, M., Esposito Vinzi, V., Chatelin, Y.M. and Lauro, C. (2005), "PLS path modeling", Computational Statistics Data Analysis, Vol. 48, No. 1, pp. 159-205.

van Herpen, E., van den Broek, E., van Trijp, H.C.M. and Yu, T. (2016), "Can a virtual supermarket bring realism into the lab? Comparing shopping behavior using virtual and pictorial store representations to behavior in a physical store", Appetite, Vol. 107, pp. 196-207.

van Herpen, E., Yu, T., van den Broek, E. and van Trijp, H. (2014), "Using a virtual grocery store to simulate shopping behaviour", proceedings of Measuring Behavior conference in Wageningen, The Netherlands.

Wang, G. (2002), "Definition and review of virtual prototyping", Journal of Computing and Information Science in Engineering, Vol. 2, No. 3, pp. 232-236.

Wansink, B. (2004), "Environmental factors that increase the food intake and consumption volume of unknowing consumers", Annual Review of Nutrition, Vol. 24, pp. 455-479.

Waterfield, B. (2008), "EU to allow sale of 'odd' shaped fruit and vegetables", The Telegraph, November 12, 2008, https://www.telegraph.co.uk/news/politics/3443343/EU-to-allowsale-of-odd-shaped-fruit-and-vegetables.html.

Waterlander, W.E., Jiang, Y., Steenhuis, I.H. and Mhurchu, C.Ni (2015), "Using a 3D virtual supermarket to measure food purchase behavior: A validation study", Journal of Medical Internet Research, Vol. 17, No. 4, p. e107.

Waterlander, W.E., Scarpa, M., Lentz, D. and Steenhuis I.H. (2011), "The virtual supermarket: An innovative research tool to study consumer food purchasing behaviour", BMC Public Health, Vol. 11, No. 1, pp. 1-10.

Waterlander, W.E., Steenhuis, I.H., de Boer, M.R., Schuit, A.J. and Seidell, J.C. (2012), "The effects of a $25 \%$ discount on fruits and vegetables: Results of a randomized trial in a three-dimensional web-based supermarket", International Journal of Behavioral Nutrition and Physical Activity, Vol. 9, No. 11, pp. 1-12.

Waterlander, W.E., Steenhuis, I.H., de Boer, M.R., Schuit, A.J. and Seidell, J.C. (2013), "Effects of different discount levels on healthy products coupled with a healthy choice label, special offer label or both: Results from a web-based supermarket experiment", International Journal of Behavioral Nutrition and Physical Activity, Vol. 10, No. 1, pp. $1-8$.

Witmer, B.G., Jerome, C.J. and Singer, M.J. (2005), "The factor structure of the presence questionnaire", Presence: Teleoperators and Virtual Environments, Vol. 14, No. 3, pp. 298-312.

Wu, J., Ju H.W., Kim, J., Damminga, C., Kim, H.-Y. and Johnson K. (2013), “ Fashion product display: An experiment with mockshop investigating colour, visual texture, and style coordination", International Journal of Retail \& Distribution Management, $\begin{array}{lllll}\text { Vol. } & 41, & \text { No. } & 10, & \text { pp. }\end{array}$ 
Table 1: Presence and ease of interaction relative ranks

\begin{tabular}{|l|c|c|c|c|c|c|c|c|c|c|}
\hline Conditions & $\begin{array}{c}\mathbf{0} \\
(\mathbf{n}=35)\end{array}$ & $\begin{array}{c}\mathbf{1} \\
(\mathbf{n}=\mathbf{3 6})\end{array}$ & $\begin{array}{c}\mathbf{2} \\
(\mathbf{n}=\mathbf{3 5})\end{array}$ & $\begin{array}{c}\mathbf{3} \\
(\mathbf{n}=\mathbf{3 6})\end{array}$ & $\mathbf{0 - 1}$ & $\mathbf{0 - 2}$ & $\mathbf{0 - 3}$ & $\mathbf{1 - 2}$ & $\mathbf{1 - 3}$ & $\mathbf{2 - 3}$ \\
\hline Presence & 71.20 & 62.79 & 71.10 & 71.17 & $\begin{array}{c}\mathrm{X}^{2}=0.720 \\
(\mathrm{p}=0.40)\end{array}$ & $\begin{array}{c}\mathrm{X}^{2}=1.029 \\
(\mathrm{p}=0.31)\end{array}$ & $\begin{array}{c}\mathrm{X}^{2}=0.001 \\
(\mathrm{p}=0.98)\end{array}$ & $\begin{array}{c}\mathrm{X}^{2}=0.647 \\
(\mathrm{p}=0.56)\end{array}$ & $\begin{array}{c}\mathrm{X}^{2}=0.710 \\
(\mathrm{p}=0.40)\end{array}$ & $\begin{array}{c}\mathrm{X}^{2}=0.950 \\
(\mathrm{p}=0.33)\end{array}$ \\
\hline $\begin{array}{l}\text { Ease of } \\
\text { interaction }\end{array}$ & 74.39 & 65.90 & 72.30 & 73.51 & $\begin{array}{c}\mathrm{X}^{2}=0.002 \\
(\mathrm{p}=0.97)\end{array}$ & $\begin{array}{c}\mathrm{X}^{2}=0.098 \\
(\mathrm{p}=0.61)\end{array}$ & $\begin{array}{c}\mathrm{X}^{2}=0.992 \\
(\mathrm{p}=0.32)\end{array}$ & $\begin{array}{c}\mathrm{X}^{2}=0.747 \\
(\mathrm{p}=0.79)\end{array}$ & $\begin{array}{c}\mathrm{X}^{2}=0.473 \\
(\mathrm{p}=0.49)\end{array}$ & $\begin{array}{c}\mathrm{X}^{2}=0.746 \\
(\mathrm{p}=0.39)\end{array}$ \\
\hline
\end{tabular}

Table 2: Consumers' perceptions relative ranks

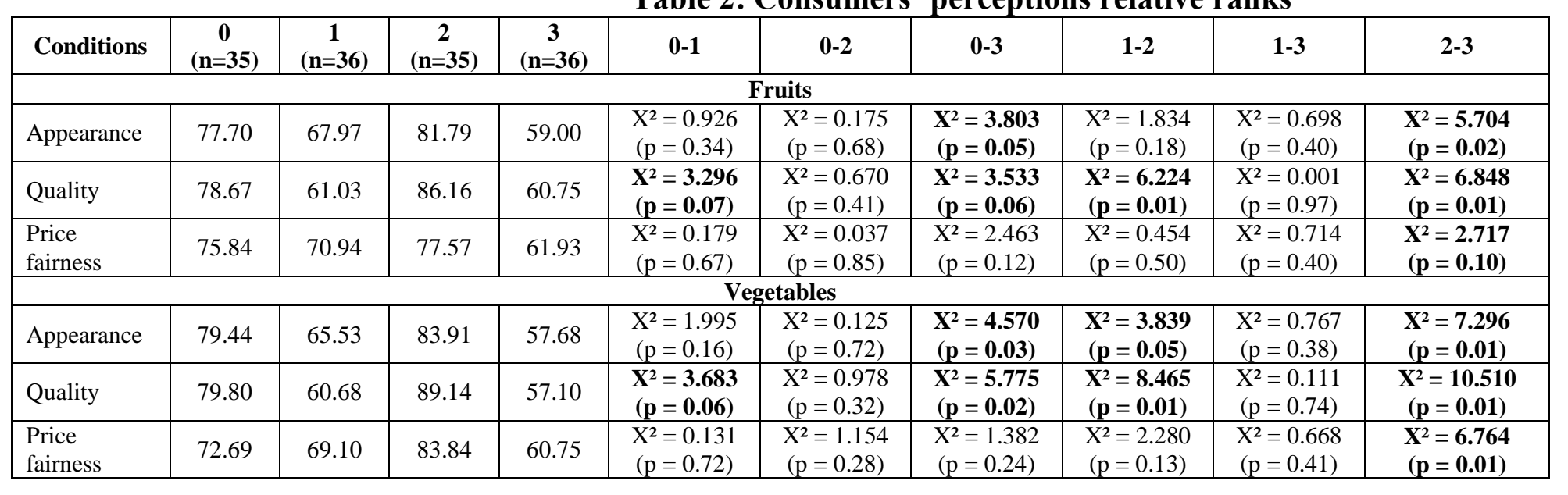

Table 3: Consumers' purchasing behavior relative ranks

\begin{tabular}{|l|c|c|c|c|c|c|c|c|c|c|c|}
\hline \multicolumn{1}{|c|}{ Conditions } & $\begin{array}{c}\mathbf{0} \\
(\mathbf{n}=35)\end{array}$ & $\begin{array}{c}\mathbf{1} \\
(\mathbf{n}=\mathbf{3 6})\end{array}$ & $\begin{array}{c}\mathbf{2} \\
(\mathbf{n}=\mathbf{3 5})\end{array}$ & $\begin{array}{c}\mathbf{3} \\
(\mathbf{n}=\mathbf{3 6})\end{array}$ & $\mathbf{0 - 1}$ & $\mathbf{0 - 2}$ & $\mathbf{0 - 3}$ & $\mathbf{1 - 2}$ & $\mathbf{1 - 3}$ & $\mathbf{2 - 3}$ \\
\hline \multicolumn{1}{|c|}{ Fruits } \\
\hline $\begin{array}{l}\text { Number of } \\
\text { products purchased }\end{array}$ & 76.94 & 75.31 & 68.87 & 64.96 & $\begin{array}{c}\mathrm{X}^{2}=0.014 \\
(\mathrm{p}=0.91)\end{array}$ & $\begin{array}{c}\mathrm{X}^{2}=0.715 \\
(\mathrm{p}=0.40)\end{array}$ & $\begin{array}{c}\mathrm{X}^{2}=1.621 \\
(\mathrm{p}=0.20)\end{array}$ & $\begin{array}{c}\mathrm{X}^{2}=0.352 \\
(\mathrm{p}=0.55)\end{array}$ & $\begin{array}{c}\mathrm{X}^{2}=1.189 \\
(\mathrm{p}=0.28)\end{array}$ & $\begin{array}{c}\mathrm{X}^{2}=0.121 \\
(\mathrm{p}=0.73)\end{array}$ \\
\hline $\begin{array}{l}\text { Time spent } \\
\text { purchasing }\end{array}$ & 73.40 & 56.10 & 70.13 & 86.39 & $\begin{array}{c}\mathrm{X}^{2}=2.556 \\
(\mathrm{p}=0.11)\end{array}$ & $\begin{array}{c}\mathrm{X}^{2}=0.184 \\
(\mathrm{p}=0.67)\end{array}$ & $\begin{array}{c}\mathrm{X}^{2}=1.572 \\
(\mathrm{p}=0.21)\end{array}$ & $\begin{array}{c}\mathrm{X}^{2}=2.649 \\
(\mathrm{p}=0.10)\end{array}$ & $\begin{array}{c}\mathrm{X}^{2}=\mathbf{9 . 5 2 3} \\
(\mathbf{p}=\mathbf{0 . 0 1})\end{array}$ & $\begin{array}{c}\mathrm{X}^{2}=\mathbf{3 . 0 9 6} \\
(\mathbf{p}=\mathbf{0 . 0 8})\end{array}$ \\
\hline \multicolumn{10}{|c|}{ Vegetables } \\
\hline $\begin{array}{l}\text { Number of } \\
\text { products purchased }\end{array}$ & 73.89 & 72.99 & 68.09 & 71.01 & $\begin{array}{c}\mathrm{X}^{2}=0.001 \\
(\mathrm{p}=0.98)\end{array}$ & $\begin{array}{c}\mathrm{X}^{2}=0.537 \\
(\mathrm{p}=0.46)\end{array}$ & $\begin{array}{c}\mathrm{X}^{2}=0.074 \\
(\mathrm{p}=0.79)\end{array}$ & $\begin{array}{c}\mathrm{X}^{2}=0.193 \\
(\mathrm{p}=0.66)\end{array}$ & $\begin{array}{c}\mathrm{X}^{2}=0.023 \\
(\mathrm{p}=0.88)\end{array}$ & $\begin{array}{c}\mathrm{X}^{2}=0.051 \\
(\mathrm{p}=0.82)\end{array}$ \\
\hline $\begin{array}{l}\text { Time spent } \\
\text { purchasing }\end{array}$ & 70.03 & 62.83 & 72.49 & 80.64 & $\begin{array}{c}\mathrm{X}^{2}=0.542 \\
(\mathrm{p}=0.46)\end{array}$ & $\begin{array}{c}\mathrm{X}^{2}=0.070 \\
(\mathrm{p}=0.79)\end{array}$ & $\begin{array}{c}\mathrm{X}^{2}=1.144 \\
(\mathrm{p}=0.29)\end{array}$ & $\begin{array}{c}\mathrm{X}^{2}=1.219 \\
(\mathrm{p}=0.27)\end{array}$ & $\begin{array}{c}\mathrm{X}^{2}=\mathbf{2 . 9 3 0} \\
(\mathbf{p}=\mathbf{0 . 0 9})\end{array}$ & $\begin{array}{c}\mathrm{X}^{2}=0.933 \\
(\mathrm{p}=0.33)\end{array}$ \\
\hline
\end{tabular}


Figure 1: Our VR supermarket, composed of four shelves of non-perishable products, FaVs stand and the cashier

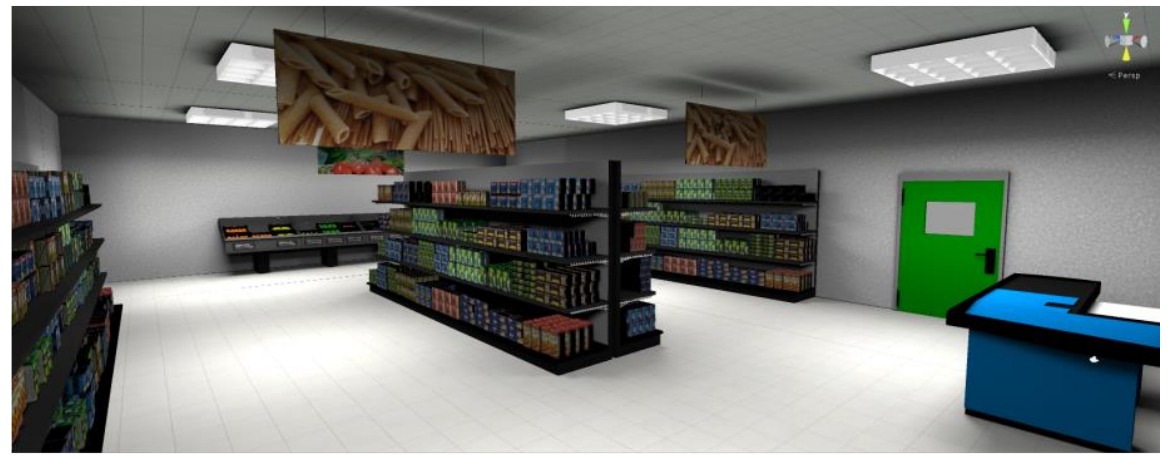

Figure 2: Example of our produce stand containing "normal" FaVs from the eight FaVs families families (oranges, bananas, pears, apples, potatoes, zucchinis, carrots and tomatoes) used in the experiment

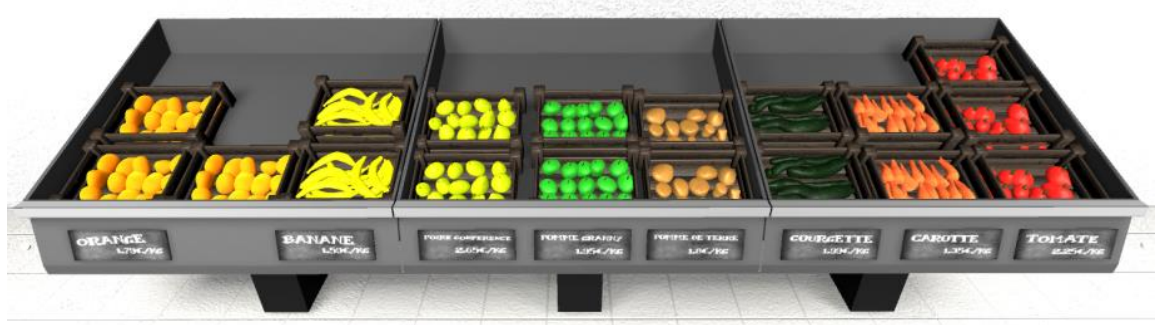

Figure 3: Automated generation (from left to right) of "normal", "slightly" misshapen, "moderately" misshapen, and "heavily" misshapen 3D models for a vegetable (here a zucchini)

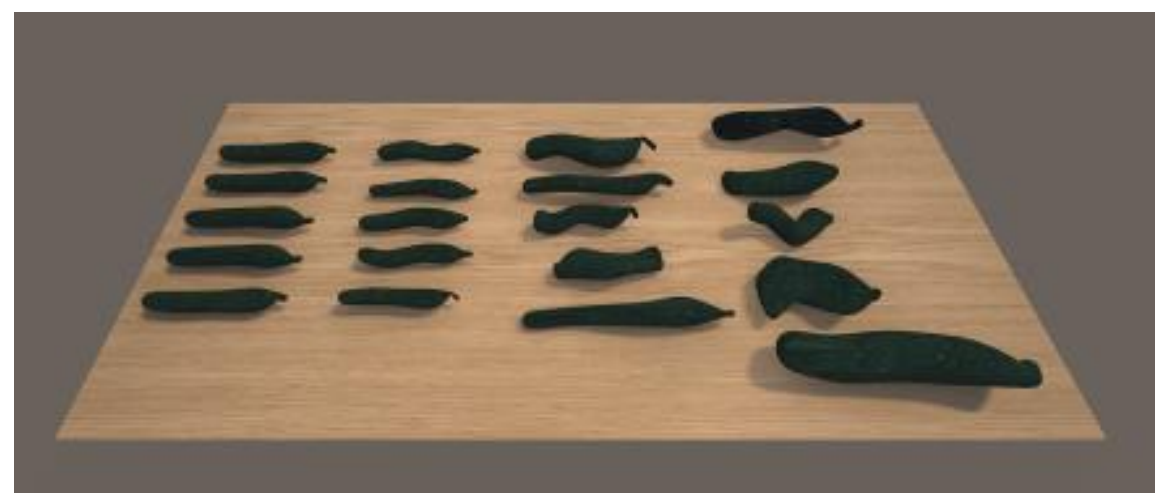




\section{Figure 4: Experimental scenario}

For your birthday, your friends offered you a "Dinner@Home" kit.

Next weekend, an amateur cook (from a famous TV show) will come to your place (either Saturday or Sunday evening, the choice is yours) and deliver a dinner (s)he will specially prepare for you and 3 of your friends in her/his workshop/kitchen. The content of the menu is kept a surprise and the cook is in charge of buying all the products (s)he will use for your menu from her/his usual suppliers, except for the fruits and vegetables that the cook let you decide about. In order for you to do the shopping, the cook gave you a budget of $20 €$ that you can spend entirely or not.

Next to your home, there are two supermarkets: one from the retailer "Super U" and one from another retailer. Today, when passing by, you decide to enter the supermarket owned by the retailer "Super U" and shop your fruits and vegetables there.

For your Dinner@Home, you have to buy at least 2 different types of fruits and at least 2 different types of vegetables of your liking in quantities that you see fit for four people.

According to your own appreciation of the offer of fruits and vegetables in "Super U"'s supermarket, you can shop either all the fruits and vegetables here or only part or none of them. Indeed, if need be, you can easily buy some more fruits and vegetables from your neighborhood's other supermarket, where you have to go tomorrow anyway to pick up a parcel from an Internet order.

Once your shopping of fresh fruits and vegetables only is done, you will go to the cashier where the goods will be "weighed" and the total value of your purchase will be displayed.

Finally, we will seek your opinion on the offer of fresh fruits and vegetables in this "Super U"'s shop.

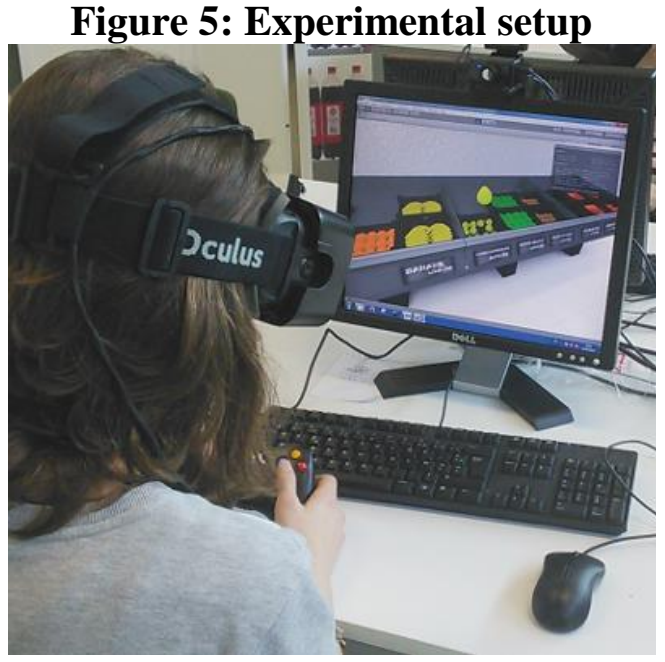




\section{Appendix 1: The semi-automatic generation process}

Our semi-automatic generation process is based on a modified generalized cylinder technique (Agin and Binford, 1976). A set of 3D objects is procedurally generated using two manually generated user inputs:

1. a base 3D skeleton;

2. a base $2 \mathrm{D}$ cross-section;

of the targeted $\mathrm{FaV}$ family (e.g. a cross-section of an apple, orange, ...).

In order to generate a set of $3 \mathrm{D} \mathrm{FaVs}$, both the base 3D skeleton and the base 2D crosssection undergo automated randomized variations in their overall shape; see Figure 4. The range of variations automatically applied depends on the required level of deformity for the FaVs.

Once the randomized skeletons are generated, the base 2D cross-section is swept along each of branches of each skeleton to generate rough 3D models. Finally, a smoothing algorithm (a Catmull-Clark subdivision method (Catmull and Clark, 1978) followed by a Laplacian smoothing operator (Taubin, 1995)) is applied to obtain the set of final automatically generated 3D models.

The virtual 3D FaVs are manually chosen from this set of automatically generated models in order to discard the less realistic ones.

Automated generation process from a "base" 3D skeleton and a "basic" cross-section of a Beefsteak Tomato.

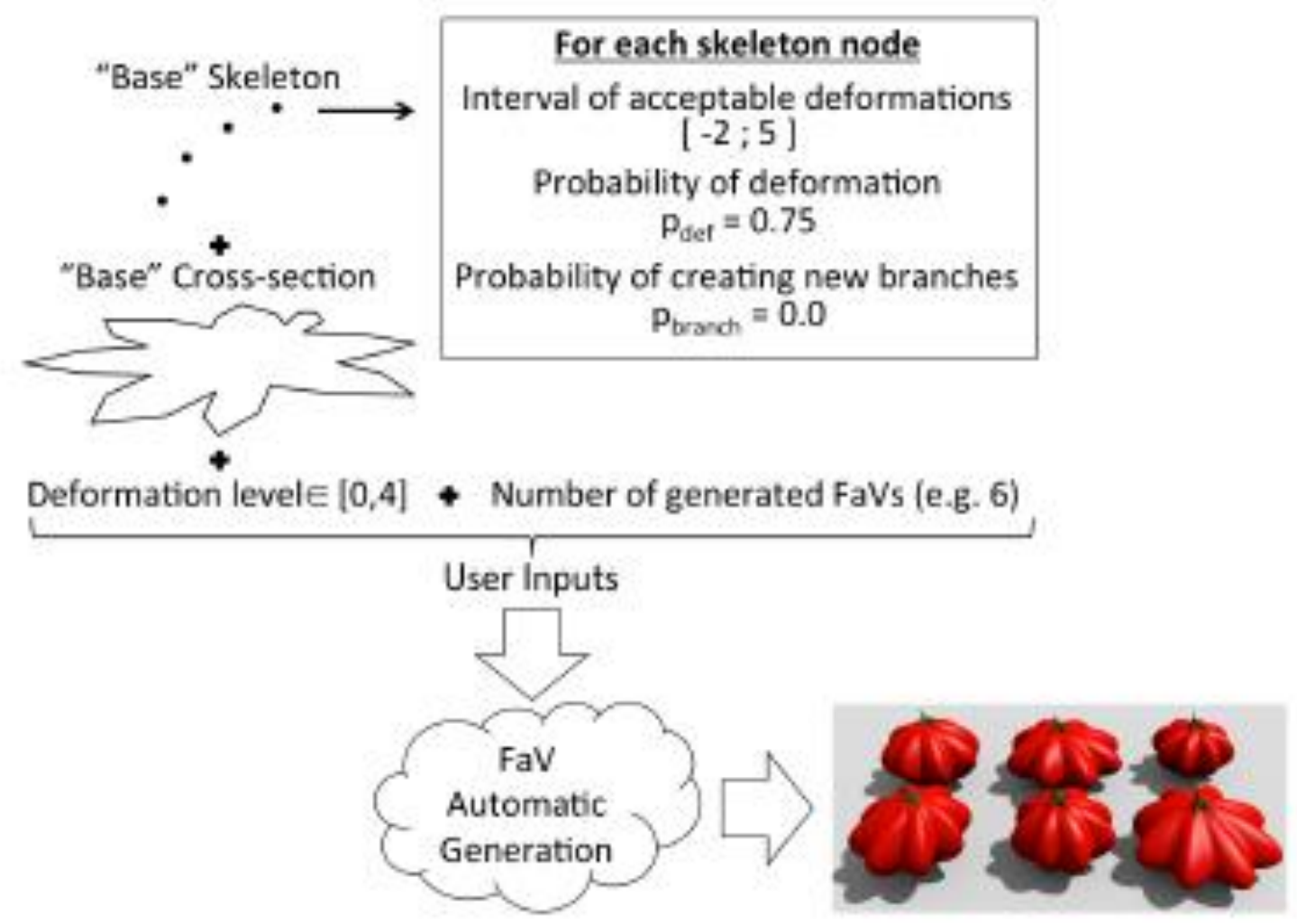


Appendix 2: Results of confirmatory factor analyses

\begin{tabular}{|c|c|c|c|c|c|c|c|c|c|c|c|c|c|c|c|c|}
\hline & \multicolumn{8}{|c|}{ Fruits } & \multicolumn{8}{|c|}{$\begin{array}{c}\text { Vegetables } \\
\end{array}$} \\
\hline & \multicolumn{2}{|c|}{$\begin{array}{c}\text { Group 0 } \\
\text { “normal” } \\
\text { FaVs } \\
\text { n=35 }\end{array}$} & \multicolumn{2}{|c|}{$\begin{array}{c}\text { Group 1 } \\
\text { "slightly" misshaped } \\
\text { FaVs } \\
\text { n=36 } \\
\end{array}$} & \multicolumn{2}{|c|}{$\begin{array}{c}\text { Group 2 } \\
\text { misshaped } \\
\text { FaVs } \\
\text { n=35 }\end{array}$} & \multicolumn{2}{|c|}{$\begin{array}{c}\text { Group 3 } \\
\text { "heavily" } \\
\text { misshaped FaVs } \\
\text { n=36 } \\
\end{array}$} & \multicolumn{2}{|c|}{$\begin{array}{c}\text { Group 0 } \\
\text { normal } \\
\text { FaVs } \\
\mathbf{n}=35\end{array}$} & \multicolumn{2}{|c|}{$\begin{array}{c}\text { Group 1 } \\
\text { "slightly" misshaped } \\
\text { FaVs } \\
\text { n=36 }\end{array}$} & \multicolumn{2}{|c|}{$\begin{array}{c}\text { Group 2 } \\
\text { misshaped } \\
\text { FaVs } \\
\text { n=35 } \\
\end{array}$} & \multicolumn{2}{|c|}{$\begin{array}{c}\text { Group 3 } \\
\text { "heavily" } \\
\text { misshaped FaVs } \\
\text { n=36 }\end{array}$} \\
\hline & $\begin{array}{c}\text { Load- } \\
\text { ing }\end{array}$ & $\mathbf{t}$ & $\begin{array}{c}\text { Load- } \\
\text { ing }\end{array}$ & ton & $\begin{array}{c}\text { Load- } \\
\text { ing }\end{array}$ & $\mathbf{t}$ & $\begin{array}{c}\text { Load- } \\
\text { ing }\end{array}$ & $\mathbf{t}$ & $\begin{array}{c}\text { Load- } \\
\text { ing }\end{array}$ & $\mathbf{t}$ & $\begin{array}{c}\text { Load- } \\
\text { ing }\end{array}$ & 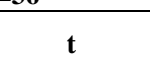 & $\begin{array}{c}\text { Load- } \\
\text { ing }\end{array}$ & $\mathbf{t}$ & $\begin{array}{c}\text { Load- } \\
\text { ing }\end{array}$ & $\mathbf{t}$ \\
\hline \multicolumn{17}{|c|}{ Appearance of the ... } \\
\hline $\begin{array}{l}\text { The color of the ... gives me the } \\
\text { impression of high-quality } \\
\text { products }\end{array}$ & 0.883 & $12.249 * * *$ & 0.930 & $15.631 * * *$ & 0.708 & $7.942 * * *$ & 0.824 & $11.378 * * *$ & 0.888 & $20.014 * * *$ & 0.958 & $18.797 * * *$ & 0.818 & $13.726^{* * *}$ & 0.916 & $24.496^{* * *}$ \\
\hline $\begin{array}{l}\text { The size of the ... gives me the } \\
\text { impression of high-quality } \\
\text { products }\end{array}$ & 0.791 & $9.773 * * *$ & 0.898 & $18.913^{* * *}$ & 0.725 & $7.666^{* * *}$ & 0.771 & $8.179 * * *$ & 0.866 & $21.345^{* * *}$ & 0.881 & $18.898^{* * *}$ & 0.804 & $9.592 * * *$ & 0.899 & $23.979 * * *$ \\
\hline $\begin{array}{l}\text { The shape of the ... gives me the } \\
\text { impression of high-quality } \\
\text { products }\end{array}$ & 0.847 & $15.537 * * *$ & 0.887 & $17.109 * * *$ & 0.671 & $5.894 * * *$ & 0.799 & $10.829 * * *$ & 0.920 & $23.336^{* * *}$ & 0.926 & $28.957 * * *$ & 0.895 & $14.665^{* * *}$ & 0.933 & $33.339 * * *$ \\
\hline $\begin{array}{l}\text { The apparent texture of the } \ldots \\
\text { gives me the impression of high- } \\
\text { quality products }\end{array}$ & 0.870 & $13.132 * * *$ & 0.899 & $20.444 * * *$ & 0.756 & $8.576^{* * *}$ & 0.900 & $14.400 * * *$ & 0.913 & $20.399 * * *$ & 0.923 & $26.441 * * *$ & 0.858 & $15.291 * * *$ & 0.948 & $25.880 * * *$ \\
\hline $\begin{array}{l}\text { The apparent freshness of the } \ldots \\
\text { gives me the impression of high- } \\
\text { quality products }\end{array}$ & 0.845 & $14.492 * * *$ & 0.722 & $7.044 * * *$ & 0.864 & $11.199 * * *$ & 0.892 & $11.506^{* * *}$ & 0.852 & $21.605^{* * *}$ & 0.832 & $15.764 * * *$ & 0.912 & $14.884 * * *$ & 0.920 & $27.769 * * *$ \\
\hline $\begin{array}{l}\text { The external appearance of the } \ldots \\
\text { gives me the impression of high- } \\
\text { quality products }\end{array}$ & 0.858 & $13.045^{* * *}$ & 0.936 & $17.509 * * *$ & 0.919 & $12.214 * * *$ & 0.837 & $9.101 * * *$ & 0.926 & $19.590 * * *$ & 0.967 & $17.396 * * *$ & 0.878 & $15.073 * * *$ & 0.930 & $33.186^{* * * *}$ \\
\hline \multicolumn{17}{|c|}{ Quality of the ... } \\
\hline $\begin{array}{l}\text { I will be satisfied by the taste of } \\
\text { the ... }\end{array}$ & 0.819 & $11.686^{* * * *}$ & 0.916 & $14.744 * * *$ & 0.718 & $8.786^{* * * *}$ & 0.904 & $19.017 * * *$ & 0.923 & $14.775^{* * *}$ & 0.932 & $15.386^{* * *}$ & 0.776 & $9.650 * * *$ & 0.952 & $14.613^{* * *}$ \\
\hline $\begin{array}{l}\text { I will be satisfied by the } \\
\text { nutritional quality of the ... }\end{array}$ & 0.740 & $6.931 * * *$ & 0.934 & $14.937 * * *$ & 0.818 & $13.151 * * *$ & 0.916 & $15.395^{* * *}$ & 0.856 & $11.503^{* * *}$ & 0.946 & $13.760 * * *$ & 0.892 & $15.323^{* * *}$ & 0.946 & $16.451 * * *$ \\
\hline $\begin{array}{l}\text { I will be satisfied by the sanitary } \\
\text { quality of the ... }\end{array}$ & 0.769 & $9.285^{* * *}$ & 0.844 & $15.338 * * *$ & 0.841 & $13.952 * * *$ & 0.898 & $16.043^{* * * *}$ & 0.734 & $8.694 * * *$ & 0.866 & $13.959 * * *$ & 0.679 & $6.533 * * *$ & 0.878 & $16.488 * * *$ \\
\hline $\begin{array}{l}\text { I will be satisfied by the ease of } \\
\text { preparation of the ... }\end{array}$ & 0.754 & $8.303 * * *$ & 0.693 & $6.027 * * *$ & 0.785 & $8.786 * * *$ & 0.844 & $8.973 * * *$ & 0.790 & $14.320^{* * *}$ & 0.673 & $4.386^{* * *}$ & 0.807 & $8.767 * * *$ & 0.811 & $9.035^{* * *}$ \\
\hline $\begin{array}{l}\text { I will be satisfied by the } \\
\text { environmental impact of the } \\
\text { production of the ... }\end{array}$ & 0.753 & $7.978 * * *$ & 0.696 & $7.586^{* * * *}$ & 0.642 & $5.475^{* * *}$ & 0.904 & $18.117 * * *$ & 0.802 & $12.581^{* * *}$ & 0.638 & $4.964 * * *$ & 0.779 & $10.234^{* * *}$ & 0.835 & $14.621 * * *$ \\
\hline $\begin{array}{l}\text { I will be satisfied by their global } \\
\text { quality }\end{array}$ & 0.880 & $9.994 * * *$ & 0.942 & $15.221 * * *$ & 0.812 & $13.494^{* * *}$ & 0.902 & $16.766^{* * *}$ & 0.921 & $14.031^{* * * *}$ & 0.954 & $14.616^{* * *}$ & 0.858 & $13.928 * * *$ & 0.914 & 20.476 \\
\hline \multicolumn{17}{|c|}{ Price fairness of the ... } \\
\hline Prices of the $\ldots$ are fair & 0.978 & $7.569 * * *$ & 0.975 & $8.231 * * *$ & 0.919 & $7.988^{* * * *}$ & 0.879 & $7.952 * * *$ & 0.974 & $9.151 * * *$ & 0.975 & $8.064 * * *$ & 0.926 & $7.640^{* * * *}$ & 0.875 & $7.301 * * *$ \\
\hline Prices of the $\ldots$ are appropriate & 0.978 & $7.569 * * *$ & 0.975 & $8.231 * * *$ & 0.919 & $7.988 * * *$ & 0.879 & $7.952 * * *$ & 0.974 & $9.151 * * *$ & 0.975 & $8.064 * * *$ & 0.926 & $7.640 * * *$ & 0.875 & $7.301 * * *$ \\
\hline
\end{tabular}

Note: *** Coefficient significant. Student's t test values greater than $|2.575|$ indicate parameters significant at $1 \%$. 
Appendix 3: Reliability indices - Jöreskog's rhô coefficients

\begin{tabular}{|c|c|c|c|c|c|c|c|c|}
\hline \multirow[b]{2}{*}{ Constructs } & \multicolumn{4}{|c|}{ Fruits } & \multicolumn{4}{|c|}{ Vegetables } \\
\hline & $\begin{array}{c}\text { Group 0: } \\
\text { “normal” FaVs } \\
\mathrm{n}=35\end{array}$ & $\begin{array}{c}\text { Group 1: } \\
\text { "slightly" } \\
\text { misshaped FaVs } \\
\text { n=36 } \\
\end{array}$ & $\begin{array}{c}\text { Group 2: } \\
\text { misshaped FaVs } \\
n=35\end{array}$ & $\begin{array}{c}\text { Group 3: } \\
\text { "heavily" } \\
\text { misshaped FaVs } \\
n=36 \\
\end{array}$ & $\begin{array}{c}\text { Group 0: normal } \\
\text { FaVs } \\
\text { n=35 }\end{array}$ & $\begin{array}{c}\text { Group 1: } \\
\text { "slightly" } \\
\text { misshaped FaVs } \\
\text { n=36 }\end{array}$ & $\begin{array}{c}\text { Group 2: } \\
\text { misshaped FaVs } \\
\mathbf{n = 3 5}\end{array}$ & $\begin{array}{c}\text { Group 3: "heavily" } \\
\text { misshaped FaVs } \\
\text { n=36 }\end{array}$ \\
\hline Appearance of the ... & 0.940 & 0.954 & 0.901 & 0.934 & 0.960 & 0.969 & 0.945 & 0.972 \\
\hline Quality of the ... & 0.907 & 0.936 & 0.898 & 0.960 & 0.935 & 0.936 & 0.914 & 0.958 \\
\hline Price fairness of the ... & 0.978 & 0.974 & 0.916 & 0.871 & 0.973 & 0.975 & 0.923 & 0.868 \\
\hline
\end{tabular}

Appendix 4: Tests of convergent and discriminant validity - Fornell and Larcker's (1981) approach

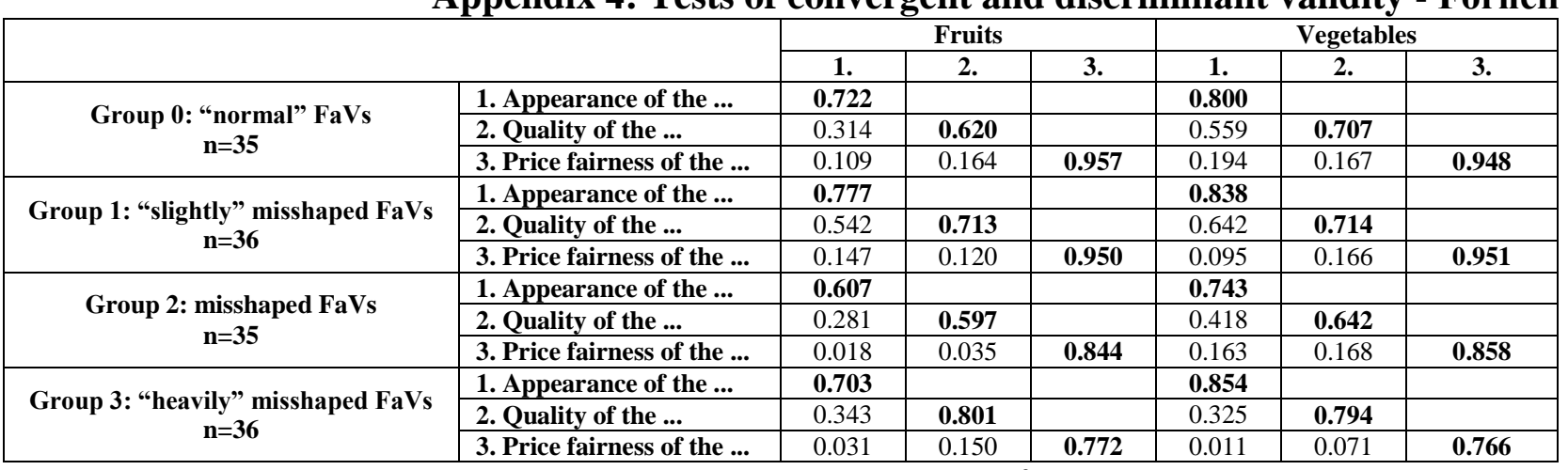

The convergent validities ( $\rho_{v c}$ ) are shown on the diagonal and the square of the correlations $\left(R_{i j}^{2}\right)$ appear below the diagonal.

Appendix 5: Tests of convergent and discriminant validity - Henseler, Ringle and Sarstedt's (2015) approach

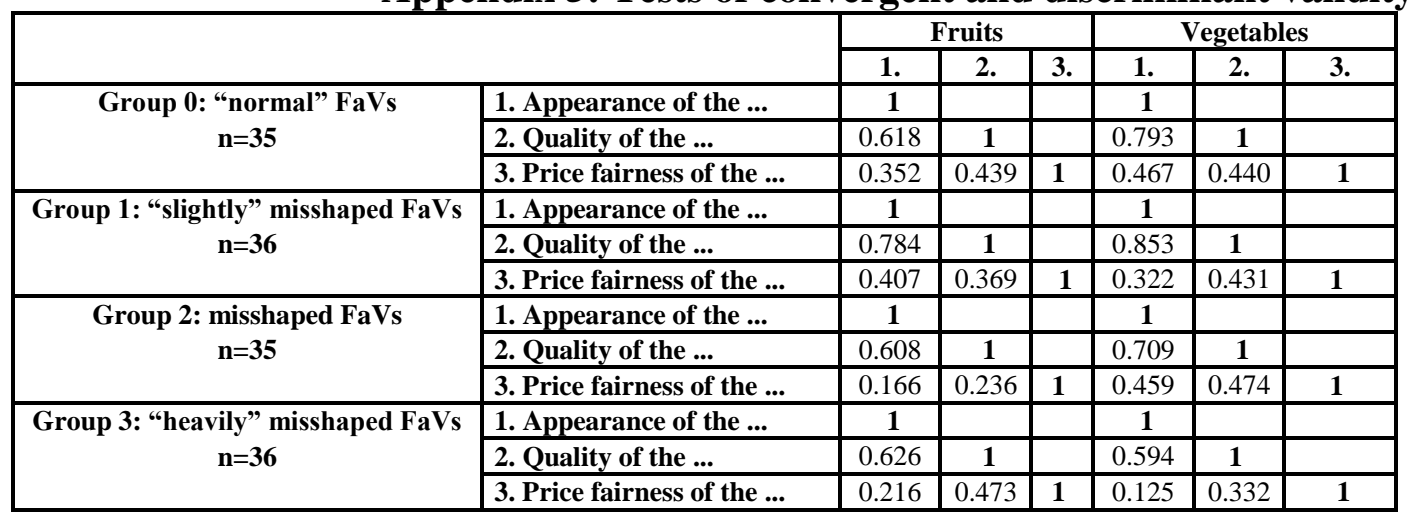

